\title{
O GRANITO PEDRA DO SAL E SUAS FEIÇÕES DE CISALHAMENTO
}

\author{
THEODOMIRO GAMA JUNIOR, PAULO SÉRgIO DE SOUSA GORAYEB e \\ FRANCISCO DE ASSIS MATOS DE ABREU*
}

\begin{abstract}
THE PEDRA DO SAL GRANITE AND RELATED SHEAR FEATURES. Detailled petrostructural ituvestigation of the Pedra do Sal Granite revealed the existence of narrow and discontinuous mylonitic zones. They correspond to NE-SW and NW-SE dextral and sinistral shear zones, respectively. The low angle stretching lineation is parallel to the shear zones. It can be identified protomylonite, mylonite, ultramylonite, and pseudotachylite from the undeformed granite to the centre of the shear zones. The analysis of the microstructures permitted the recognition of five petrographic-structural domaines, in which it can be observed the progressive textural and mineralogical transformations. The six principal mineral phases behaved differently under deformation. Quartz is recrystalized and shows essentially ductile deformation. Plagioclase and microcline by their turn show a brittle-ductile behaviour and have been recrystalized only at advanced stages of deformation. Finally, amphibole and titanite are esencially brittle. Besides the mylonitic foliation, other identified microstructures are microfactures, kinkbands, pressure shadows, microboudinage, bending and stretched minerals followed by cumminution and dynamic recristalization. These features suggest a progressive brittle-ductile shearing process related to a major strike-slip motion under metamorphic condictions varying from low amphibolite to high greenschist facies.
\end{abstract}

\begin{abstract}
RESUMO Zonas milonfticas estreitas e descontínuas foram reveladas por meio de investigação petroestrutural detalhada no Granito Pedra do Sal. Correspondem a zonas de cisalhamento NE-SW (dextral) e NW-SE (sinistral). Uma lineação de estiramento de baixo ângulo é paralela às zonas de cisalhamento. Podem ser identificados protomilonitos, milonitos, ultramilonitos e pseudo taquilitos desde o granito indeformado até o centro das zonas. A análise das microestruturas possibilitam reconhecer cinco domínios petrografico-estruturais, nos quais se podem observar as transformaçóes texturais e mineralógicas progressivas. As seis fases mineralogicas principais comportaram-se diferentemente durante a deformaçăo. $O$ quartzo 6 recristalizado e mostra deformaçäo essencialmente dúctil. O plagioclásio e a microclina, por sua vez, mostram comportamento réptil-dúctil e são recristalizados apenas em est́́gios avançados da deformação. Finalmente, o antibólio e a titanita sáo essencialmente rúpteis. Alem da foliação milonítica, outras microestruturas identificađas são microfraturas, kinkbands, sombras de pressão, microbudinagem, encurvamento e minerais estirados, sucedidos por cominuição e recristalização dinâmica. Estas feiçốes são sugestivas de um processo de cisalhamento progressivo rúptil-dúctil, relacionado a um movimento principalmente de transcorrência, sob condiçōes metamórficas variando de fácies anfibólito baixo para xistos verdes alto.
\end{abstract}

INTRODUCÃ̃o Na região costeira do Estado do Piaú, aproximadamente a $11 \mathrm{~km}$ a norte da cidade de Parnafba, aflora, na ponta da Pedra do Sal, um corpo de rocha granítica que se destaca em meio aos sedimentos recentes da praia e as águas do Oceano Atlântico (Fig. 1). Por isso não é possível definir suas dimensão nem suas relaçöes de contato com as rochas adjacentes.

Nos trabalhos anteriores, muito poucas informaçóes geológicas săo encontradas sobre este corpo. As investigaçó̌s de campo e os estudos petrograficos permitiram a caracterização de feiçöes estruturais ligadas a um evento de cisalhamento frágil-dúctil, que impôs modificaçôes importantes nos arranjos texturais ígneos pretéritos.

Este artigo se propōe descrever as características mineralogicas e microestruturais peculiares do Granito Pedra do Sal e, de forma especial, analisar as tramas relacionadas aos efeitos do cisalhamento frágil-dúctil concentrado em zonas preferenciais de deformação. Pretende-se ainda discutir a posiçáo do corpo no contexto geológico regional.

O CONTEXTO GEOLÓgICO REGIONAL As relaços geologicas de campo entre o Granito Pedra do Sal e as rochas regionais adjacentes não săo conhecidas, pois este corpo se encontra circundado por sedimentos praieiros recentes. As informaçôes da geologia de superfície, em afloramentos do Granitóide Chaval, situado a cerca de $60 \mathrm{~km}$ a SE e $40 \mathrm{~km}$ a S do Granito Pedra do Sal, indicam que toda a área de ocorrência desse litótipo foi envolvida por processos tectônicos e geraçăo de elementos estruturais que, de acordo com as dataçóes pelos métodos K/Ar em biotita (Almeida et al. 1968) e Rb/Sr em rocha total (Araújo Neto, em prep.), estăo relacionados ao Evento Brasiliano.

Os dados provindos dos estudos geocronológicos (método $\mathrm{K} / \mathrm{Ar}$ e $\mathrm{Rb} / \mathrm{Sr}$ ) dos testemunhos de sondagem executados pela Petrobrás (Cordani et al. 1984), entre os Granito Pedra do Sal e os afloramentos de rochas cristalinas do Cráton Săo Luís (a $S$ e SE da capital maranhense), indicam também a incidência daquele evento.

A análise da informaçấo gravimétrica (Lesquer et al. 1984, Abreu, em prep.) mostra que a estruturação geologica de todo esse segmento crustal, no qual se insere o corpo em estudo, segue um padrão NE-SW com eixos de anomalias gravimétricas positivas e negativas.

Sedimentos fanerozóicos da Bacia Sedimentar do Parnaiba, relacionados às unidades litoestratigráficas Serra Grande, Pimenteiras e Cabeças, ocorrem um pouco mais a sul, marcando o relevo ém cuesta da borda dessa bacia.

A Formaçäo Barreiras de idade terciária tem distribuição areal importante recobrindo as regiōes a sul e leste do local de afloramento do Granito Pedra do Sal.

Estruturalmente, a região é marcada por um forte padrăo NE-SW em feiçōes geométricas penetrativas meso e macroscópicas. Dentre elas merecem destaque a foliação milonítica, estatisticamente tombada para NW, e as lineaçōes de estiramento mineral com baixos valores de mergulho, orientadas NE-SW.

Esses elementos configuram um sistema direcional denominado por Abreu et al. (1988). de Cinturäo de Cisalhamento Noroeste do Ceará, o qual teria prosseguimento para oeste até as proximidades da capital maranhense, onde ocorrem rochas relacionadas ao denominado Cráton Sáo Luís (Fig. 2). O corpo granítico Pedra do Sal, registrando a 


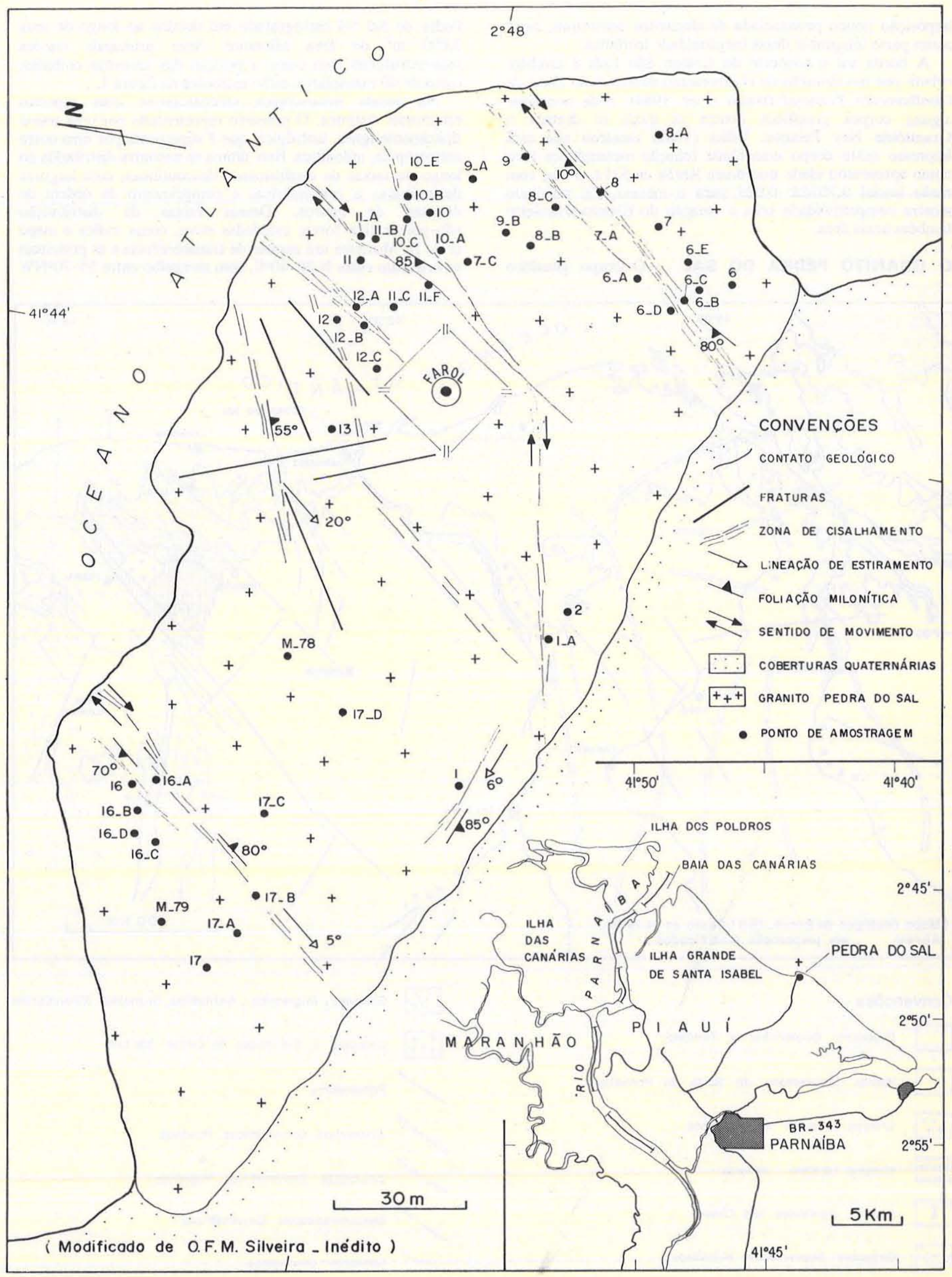

Figura 1 - Mapa geológico do Granito Pedra do Sal 
imposição pouco pronunciada de elementos estruturais, seria assim parte integrante dessa megaunidade tectônica.

A borda sul e sudoeste do Cráton São Luís é também orlada por um cinturão de cisalhamento denominado Zona de Cisalhamento Tentugal (Hasui et al. 1984), onde ponteiam alguns corpos graníticos dentre os quais se destaca o Granitóide Ney Peixoto. Villas (1982) mostrou que está impresso neste corpo uma tênue foliação metamórfica bem como apresentou idade isocrônica $\mathrm{Rb} / \mathrm{Sr}$ de $521 \pm 41 \mathrm{Ma}$, com razão inicial $0,7076 \pm 0,029$ para o mesmo. Tal resultado mostra compatibilidade com a atuação do Evento Brasileiro também nessa área.

O GRANITO PEDRA DO SAL O corpo granítico
Pedra do Sal foi cartografado em detalhe ao longo de seus $3.000 \mathrm{~m}^{2}$ de área aflorante. Suas principais feições mesoestruturais bem como a posição das amostras colhidas, cerca de 40 exemplares, estão indicadas na figura 1.

$\mathrm{Na}$ escala mesoscópica identificam-se dois aspectos estruturais distintos. $\mathrm{O}$ primeiro representado por uma trama tipicamente ígnea, isotrópica, que é superposta por uma outra anisotrópica, milonítica. Esta última se encontra distribuída ao longo de faixas de cisalhamento descontínuas, com larguras decimétricas a centimétricas e comprimento da ordem de dezenas de metros. Dessas faixas de distribuição não-penetrativa foram estudadas nove, como indica o mapa (Fig. 1). Mostram um caráter de transcorrência e as principais se orientam entre $\mathrm{N} 20-40^{\circ} \mathrm{E}$, com mergulho entre $55-70^{\circ} \mathrm{NW}$

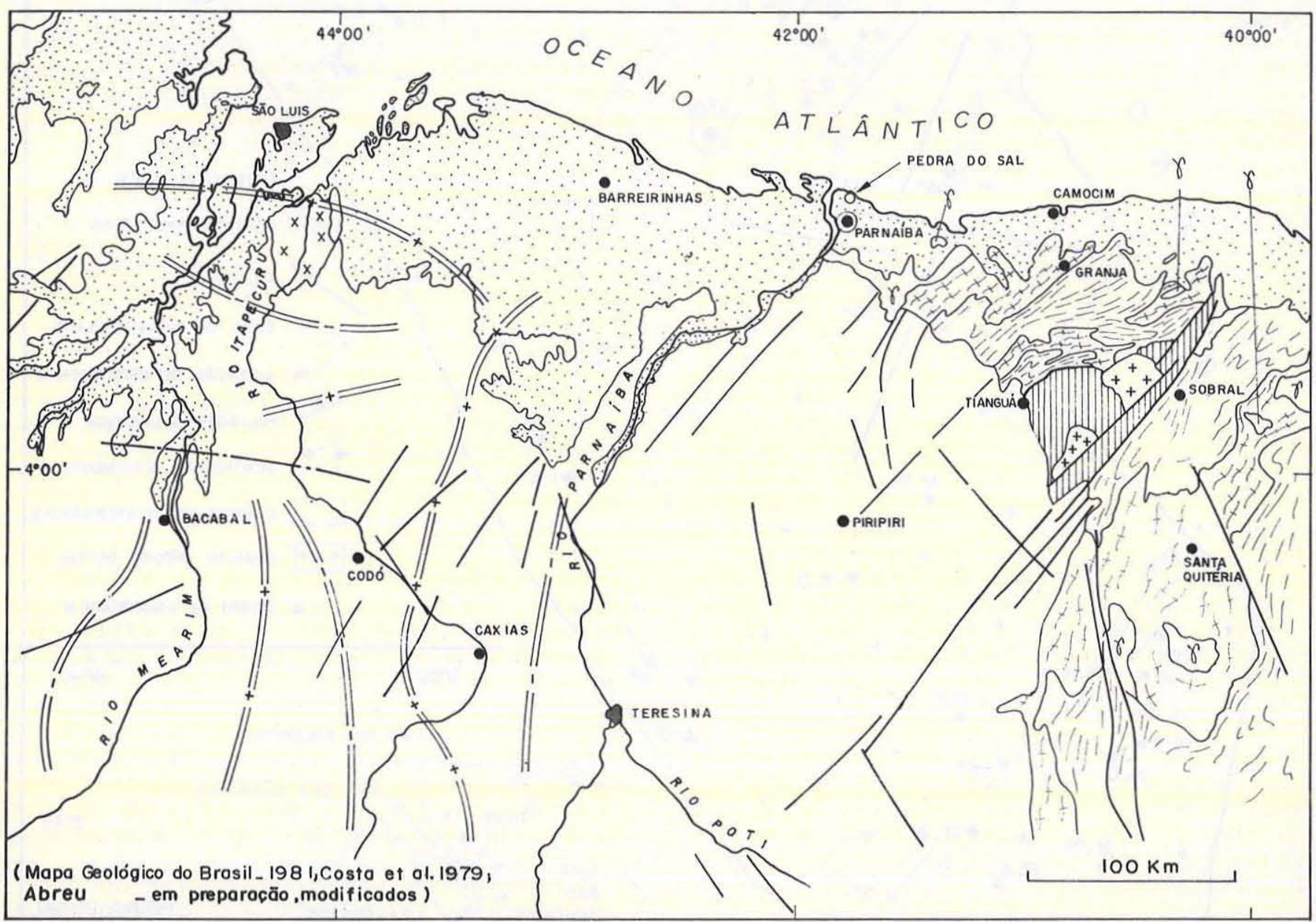

\section{Convençōes}

Cobertura Quaternária e Terciária

Rochas Sedimentares da Bacia do Parnaíba

Granitos Intrusivos tipo Meruoca

Sistema Ubajara - Jaibaras

$\gamma$ Augen - granitoides tipo Chaval

Conjuntos Supracrustais Miloníticos
Gnaisses, Migmatitos , Anfibolitos, Granulitos Milonitizados

$x$
$x$
$x$ Gnaisses e Granitoides do Craton Säo Luis

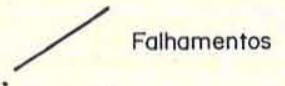

Anomalias Gravimétricas Positivas

Anomalias Gravimétricas Negativas

Descontinuidades Gravimétricas

Contatos Geológicos

Figura 2 - Mapa geológico esquemático da porção norte dos Estados do Ceará, Piauí e Maranhão 
até verticais, de movimentação dextral. Algumas dessas faixas variam de direção até E-W e raramente invertem seu caimento. Existem outras faixas menos expressivas orientadas entre $\mathrm{N} 40-60^{\circ} \mathrm{W}$, de alto mergulho e com movimentação sinistral. A lineação de estiramento apresenta valores de mergulho normalmente baixos até $10^{\circ}$, sendo que localmente atingem $20^{\circ}$, e pode ser observada com maior nitidez nas faixas de orientação NE com mergulho para $220^{\circ} \mathrm{Az}$. Aproximando-se dessas faixas e adentrando as mesmas, observa-se uma variação na granulometria e nos aspectos texturais das rochas. Nota-se que a partir de porções praticamente não deformadas, com granulação grossa a média e textura ígnea preservada, passa-se gradativamente à ocorrência de protomilonitos, milonitos e ultramilonitos nas partes mais internas das faixas, as quais se relacionam à intensificação progressiva da deformação frágil-dúctil cisalhante. Pseudotaquilitos ocorrem também na forma de finos leitos.

\section{DOMINIOS PETROGRÁFICO-ESTRUTURAIS O}

entendimento e a definição de rochas miloníticas têm sido revistos nos últimos anos a partir dos estudos de Spry (1969), Higgins (1971) e Sibson (1977), demonstrando-se que as rochas nas zonas de cisalhamento são deformadas plasticamente e sofrem simultânea recristalização dinâmica (Bell \& Etheridge 1973, 1976, White 1976, 1977, Mitra 1978, 1979, White et al. 1980), sendo que, em muitos casos, se pode acompanhar, progressivamente, as transformaçōes acontecidas. As classificaçöes e discussōes apresentadas neste trabalho, estão baseadas nessas novas proposiçōes de estudo para rochas miloníticas.

A partir de critérios microestruturais, auxiliados por feições mesoscópicas, as rochas foram separadas em cinco domínios estabelecidos numa seqüência progressiva de deformação cisalhante, reduçâo do tamanho dos grảos e recristalização dinâmica: a. granito isotrópico e levemente deformado; b. granito pouco deformado com início de recristalização; c. protomilonitos foliados com recristalização acentuada; d. milonitos fortemente foliados; e. ultramilonitos.

Embora não estejam relacionadas a esta seqüência progressiva da deformação frágil-dúctil cisalhante também estão presentes finas lentes, milimétricas, de pseudotaquilitos. Estes serão descritos juntamente com os ultramilonitos (domínio E), já que ocorrem intimamente associados.

Esta seqüência pode ser acompanhada transversalmente às faixas de cisalhamento, desde as porções mais afastadas delas, onde as feiçōes primárias estão presentes (domínio A), até o seu centro, onde se impõe uma trama milonítica (domínios D e E), conforme a seqüência da figura 3. Esses domínios serão descritos em detalhe a seguir.

Domínio A As rochas deste domínio são típicos granitos leucocráticos, com índice de cor entre 5 e 11, e coloração rosada com leves tons cinza. Sảo eqüigranulares e têm granulação média a grossa (Fig. 3 a, b). Petrograficamente, são granitos normais. situados na extremidade inferior do subcampo 3b (monzogranito) do diagrama de Streckeisen (1976). Apresentam textura granular hipidiomórfica e xenomórfica constituída essencialmente por álcali-feldspatos, plagioclásio e quartzo. As fases máficas estão representadas por anfibólio e biotita, e como acessórios encontram-se titanita, apatita e mais raramente opacos e zircão.

$\mathrm{O}$ plagioclásio é do tipo oligoclásio $\left(\mathrm{An}_{28}\right)$, representado por cristais normalmente subédricos; com geminação do tipo albita, albita-carlsbad e albita-periclínio. Alguns cristais se encontram microfraturados, encurvados e exibem uma extinção ondulante fraca a moderada. No contato com o álcali-feldspato são encontrados intercrescimentos do tipo mirmequítico. Cristais de sericita, epídoto e carbonatos ocorrem raramente como produtos de alteração.
O álcali-feldspato é do tipo microclínio e se apresenta normalmente subautomórfico e eventualmente xenomórfico. Contém inclusỏes de hornblenda automórfica e por vezes biotita e plagioclásio geralmente corroído. Intercrescimentos pertíticos nâo são muito freqüentes mas, quando estão presentes, são do tipo filetes orientados. Efeitos de deformação nos cristais de álcali-feldspato também são registrados, especialmente microfraturas e extinção ondulante fraca.

O quartzo ocorre nos interstícios dos demais minerais na forma de cristais anédricos, normalmente com extinção ondulante fraca a moderada e contatos curvos e retos, por vezes, suturados.

Entre as fases máficas, geralmente predomina o anfibólio prismático e subédrico, freqüentemente com maclamento simples, com cores de pleocroísmo variando de marrom-amarelado $(X)$, verde-amarronzado $(Y)$ e verde-oliva (Z), e com ângulo de extinção em torno de $18^{\circ}$, o que permite defini-lo como do tipo hornblenda. A biotita ocorre como palhetas subédricas e anédricas, com formas irregulares e cores de pleocroísmo variando de marrom $(\mathrm{Z}=\mathrm{Y})$ e marrom-pálido (X).

Dentre os minerais acessórios estão presentes titanita, zircão, apatita e opacos. $\mathrm{O}$ primeiro se destaca por sua maior quantidade e pela forma perfeitamente losangular, ocorrendo disseminado na rocha e como inclusōes na hornblenda. Dessa forma, as rochas do domínio A se caracterizam por apresentar uma textura ígnea típica de granitos normais. Os efeitos da deformação cisalhante frágil-dúctil são tênues e se observam somente em alguns minerais, especialmente no quartzo e nos feldspatos, sob a forma de microfraturas e extinção ondulante fraca a moderada. Os efeitos de recristalização são quase imperceptíveis, sendo reconhecidos apenas nos cristais de quartzo, que formam subgrãos com limites suturados, e nas microfraturas.

Domínio B Mesoscopicamente, as rochas deste domínio apresentam pequenas diferenças em relação às do domínio $\mathrm{A}$, ressaltando uma coloração menos rosada e uma incipiente orientação. Em seções delgadas, no entanto, as diferenças são mais significativas, especialmente em relação a seus aspectos microestruturais. Estes são destacados pela presença de porfiroclastos de microclínio, plagioclásio, anfibólio, e algum quartzo deformados, envolvidos por uma matriz granoblástica de granulação mais fina (Fig. 4), composta principalmente por cristais de quartzo pouco orientados e localmente estirados. Os porfiroclastos têm forma arredondada e sāo bem mais abundantes que a matriz, de tal forma que quase se tocam (Fig. 3 c, d).

Os porfiroclastos de plagioclásio se mostram normalmente encurvados, desenvolvendo kinkbands e microfraturamento interno, permitindo que suas lamelas de geminação se tornem irregulares, descontínuas e truncadas. Ao longo das microfraturas ocorrem uma cominuição e recristalização dinâmica do próprio plagioclásio na forma de agregados microcristalinos, com geração de epídoto. Alguma sericitização é observada localmente.

Os cristais de microclínio mostram comportamento similar aos de plagioclásio, apresentando extinção ondulante moderada a forte, formação de subgrãos e microfraturas. Seus contornos são irregulares e mostram contatos denteados e até rodeados por agregados finos, granularizados por recristalização (mortar). Essas feições são também desenvolvidas ao longo das microfraturas, que, em alguns casos, chegam a segmentar os cristais em dois ou mais pedaços (Fig. 5).

A hornblenda deste domínio, em comparação com a do anterior, é muito similar, observando-se apenas pequenas fraturas e raros cristais quebrados ou levemente encurvados. No entanto, ao longo das microfraturas e nas bordas de alguns 

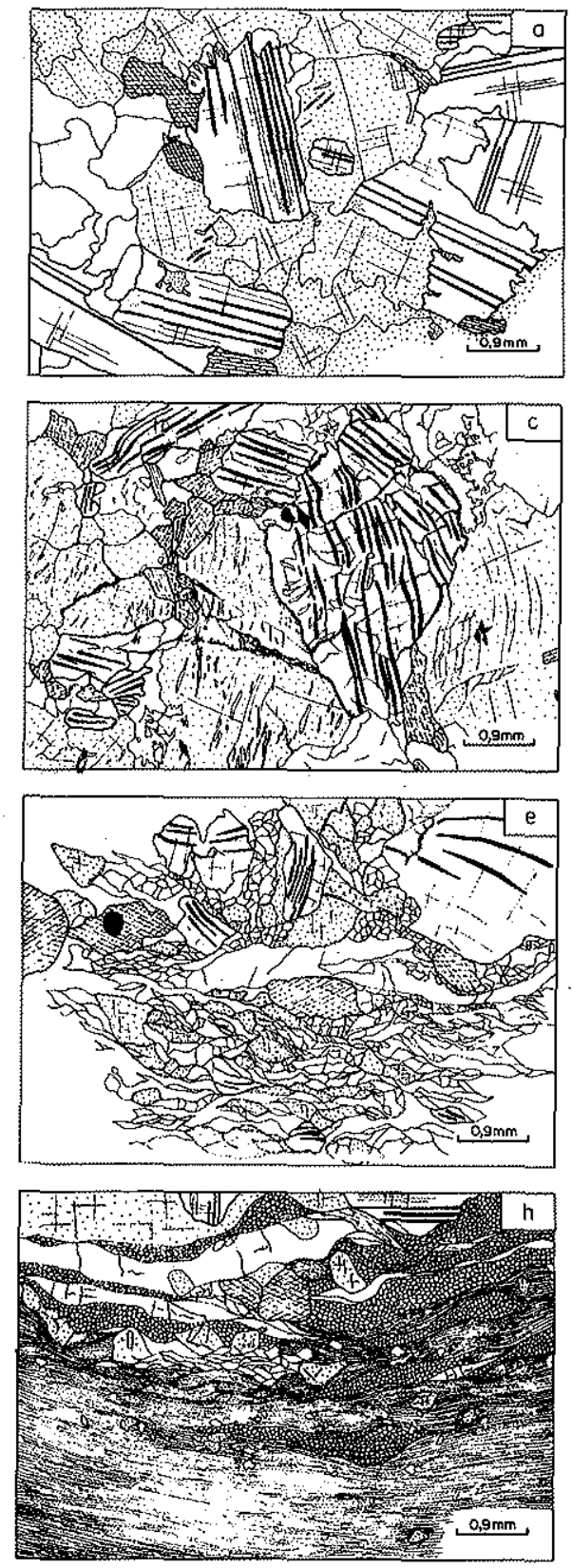

Simbolos das figuras

(11) Plogiocldsio

(3) K _ Feldspoto (microclinio, pertítico ou nōo )

$$
\text { Biotita }
$$

Yornblendo

Q0 Quartzo

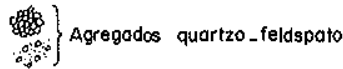

- Fitanito

Material Vitreo

Niveis uftramiloniticos $(a z+f+b i)$

pI - plagioclósio

$f$ - feldspato

qz - quartzo

bi- biotito

hb- hornblendo
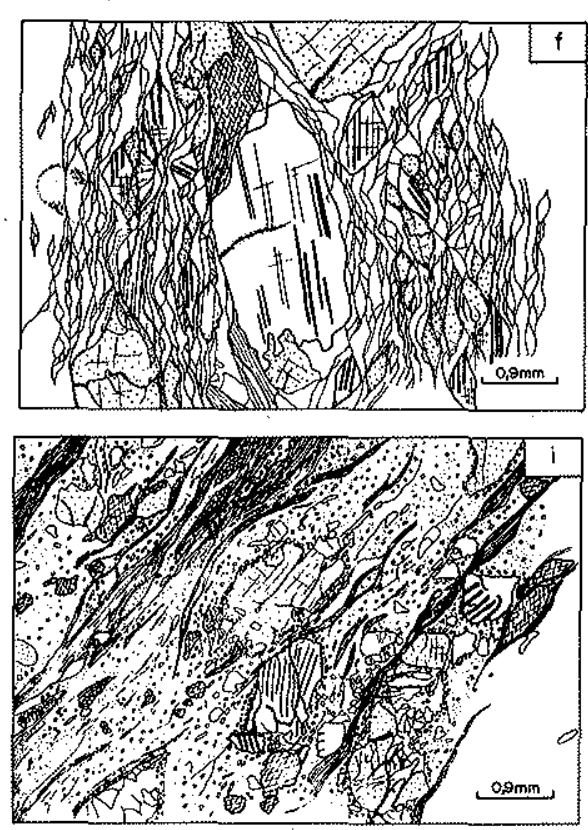
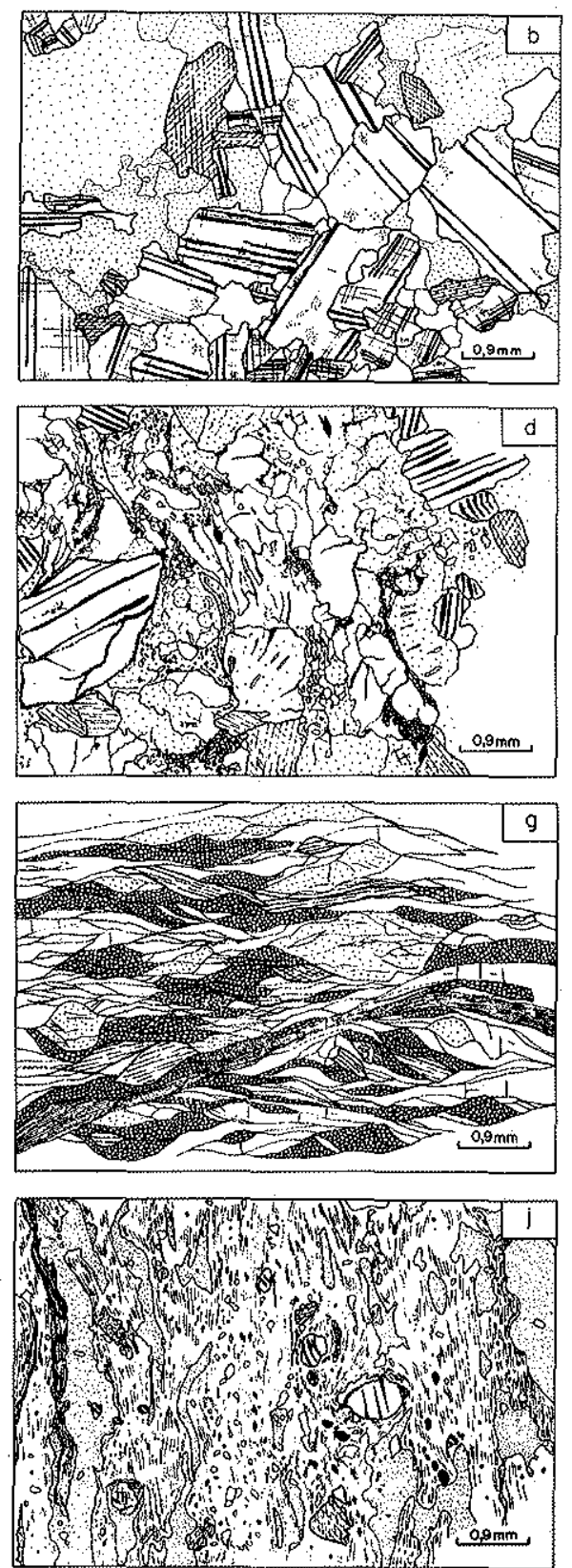

Figura 3 - Dominios petrográfico-estruturais no Granito Pedra do Sal mostrando a variação da deformação cisalhante nas faixas miloníticas. a, b. domínio A - granito isotrópico a levemente deformado; $\mathbf{c}, \mathbf{d}$. domínio $B$ - granito pouco deformado com intcio de recristalização; e, f. dominio $C$ - protomilonitos foliados com recristalização acentuada; $\mathbf{g}$. dominio $D$ - milonitos fortemente foliados; $\mathbf{h}, \mathbf{i}, \mathbf{j}$. domínio $E$ - ultramilonitos e pseudotaquilitos. Os mesmos símbolos são adotados nas figuras de 4 a 8.

cristais, chegam a se desenvolver pequenas palhetas de biotita verde e cristais de epídoto, que resultam da transformação da hornblenda.

$O$ quartzo mostra uma forte extinção ondulante com a formação de subgrăos, estiramento acentuado em certos locais (ribbon) e está geralmente recristalizado. São raros os cristais maiores deste mineral, posto que geralmente o quebramento e a recristalizaçăo os transformam em agregados granoblásticos, poligonizados ou não. Alguns cristais, no entanto, estão parcialmente preservados $\mathrm{e}$, em seu núcleo, os subgrãos săo rodeados por agregados poligonais de granulaçăo bem mais reduzida (recristalização dinámica).

A biotita geralmente se encontra encurvada, retorcida e com bordas quebradas, ao longo das quais se recristalizam palhetas menores de biotita e agregados microcristalinos de epídoto. Essas palhetas mostram uma tonalidade mais esverdeada de pleocró́smo.

A titanita ocorre disseminada na rocha e como inclusőes no anfibolio, mantendo sua forma original.

Nas rochas deste domínio, a deformaçăo cisalhante juntamente com os processos de cominuição e recristalização imprimem modificaçőes significativas na trama fgnea original, a qual ainda pode ser identificada. As feiçőes microestruturais estäo representadas pelos porfiroclastos microfraturados e pelos cristais de quartzo estirados em meio a uma matriz fina de agregados granoblásticos seriados ou năo. As transformaçōes mineralógicas incipientes das fases máficas são também aspectos importantes neste domínio. 
Domínio C As rochas desse domínio diferem das dos domínios anteriores por apresentarem a superimposição de uma trama anisotrópica marcante, relacionada ao incremento progressivo da deformação cisalhante e da recristalização dinâmica (Fig. 3 e, f).

Mesoscopicamente, caracterizam-se por apresentar coloração cinza-esbranquiçada, granulação fina e notável estiramento dos minerais, compondo uma foliação milonítica do tipo S. Está é definida pela relação entre os porfiroclastos de feldspatos estirados, envolvidos por minerais máficos e cristais de quartzo fitados. Ressalta-se uma outra superfície em posição oblíqua à anterior, a qual é descrita como uma foliaçaō de cisalhamento do tipo $\mathbf{C}$. A relação entre $\mathbf{S}$ e $\mathbf{C}$ imprime um arranjo sigmoidal à foliação representando uma feição estrutural notável entre as rochas deste domínio (Fig. 6). Nota-se também a presença de faixas descontínuas, irregularmente alternadas, nas quais aconteceu a segregação dominante de minerais máficos ou félsicos, levando à composição de um bandamento incipiente.

Em seção delgada, a foliação $\mathbf{S}$ é definida pela orientação de porfiroclastos ocelares de feldspatos e anfibólio, palhetas de biotita marrom, cristais de quartzo fitados e lentes, constituídas por minerais microcristalinos. A foliação $\mathbf{C}$ é representada por cordões orientados de cristais microcristalinos (quartzo, feldspatos e epídoto) e pequenas palhetas de biotita verde, geradas a partir das transformações do anfibólio e da biotita marrom.

Neste domínio se destacam faixas estreitas, descontínuas e irregulares, de granulação fina, constituídas predominantemente por cristais de quartzo e feldspatos em meio a outras ineqüigranulares formadas por porfiroclastos de plagioclásio, microclínio, hornblenda e titanita envolvidos numa matriz fina quartzo-feldspática com palhetas de biotita. Essas feições chegam a ressaltar um bandamento quando se intercalam faixas de quartzo fitado com outras mais ricas em máficos.

Os porfiroclastos estão extremamente deformados individualmente, com formas amendoadas e geralmente apresentando recristalização em suas bordas. Alguns cristais de plagioclásio e microclínio, por exemplo, exibem microfalhamentos com deslocamentos sucessivos tão regulares que chegam a curvar o cristal. A recristalização se torna acentuada e parte dos porfiroclastos se agregam à matriz. A segmentação dos cristais e a formação de kinkbands são microestruturas freqüentes. Comparativamente, no entanto, nota-se que a hornblenda e a titanita não apresentam tão marcadamente essas feições e não mostram estiramento, indicando uma resistência muito maior à deformação.

Nas faixas félsicas destacam-se duas feições microestruturais dos cristais de quartzo. Uma é definida por cristais muito estirados, lentiformes e lineares (ribbon quartz), acompanhando a orientação da rocha, e outra representada por agregados microcristalinos, formando pequenas lentes em contatos subdenteados ou poligonizados, resultantes da recristalização de grãos maiores.

As faixas máficas são formadas principalmente de porfiroclastos de hornblenda, orientados ou não, transformados nas bordas e nas microfraturas para biotita verde e epídoto. Nas faixas mais deformadas, esta transformação se encontra em um estágio tão avançado que os cristais de hornblenda tendem a diminuir de tamanho e quantidade (Fig. 7).

A partir deste domínio a trama anisotrópica, representada pelas foliações miloníticas $\mathbf{S}$ e $\mathbf{C}$, impõe-se de forma tão rigorosa e sistemática que a textura ígnea pretérita não pode ser mais reconstituída e as rochas representam típicos protomilonitos. Nestes, além das foliaçóes $\mathbf{S}$ e $\mathbf{C}$, os cristais responderam à atuação da deformação de maneira frágil e dúctil. Assim, os porfiroclastos de feldspatos tornaram-se ocelares e intensamente microfraturados enquanto o quartzo sofreu importante estiramento. A atuação dos processos de cominuição e recristalização dinâmica foi significativa enquanto as transformações mineralógicas passaram a exercer um importante papel na definição da trama anisotrópica, chegando até a segregar minerais, originando um aspecto bandado na rocha.

Domínio D Este domínio está localizado na parte central das faixas de cisalhamento. As rochas apresentam diferenças notáveis na coloração e granulometria quando comparadas àquelas dos domínios anteriores. São cinza-escuras, afaníticas, com raros porfiroclastos isolados em uma matriz de granulação fina. Desenvolve uma conspicua foliação milonítica a qual, em amostra de mão, é de difícil recnhecimento em virtude da significativa redução na granulometria. Em seções delgadas, porém, é facilmente identificada (Fig. 3 g). Localmente, leitos segregados de quartzo, descontínuos e milimétricos, estão distribuídos paralelos à foliação. Com o acréscimo progressivo na intensidade da deformação, as foliações $\mathbf{S}$ e $\mathbf{C}$ tendem a se paralelizar, embora localmente se observem fatias lentiformes, preservadas da deformação, isoladas entre a foliação milonítica mais evoluída. Neste caso, a relação $\mathbf{S} / \mathrm{C}$ pode ser ainda reconhecida (Fig. 8a). Localmente, também se observa que a foliação $\mathbf{S}$ é microdobrada ao curso seguinte do processo de deformação progressiva.

A lineação de estiramento não é muito evidente, embora possa ser reconhecida pela orientação dos ocelos e lentes.

Ao microscópio, observa-se que os porfiroclastos são principalmente de plagioclásio, microclínio e raramente hornblenda, os quais estão isolados em uma matriz fina, microcristalina. Os porfiroclastos estão bem mais estirados do que os do domínio anterior, destacando-se sob a forma de amêndoas e lentes delgadas chegando até a constituir ribbons e microboudinage em cristais de plagioclásio. Ao redor de cristais de feldspatos comumente se desenvolvem agregados recristalizados bem finos, definindo texturas mortar, enquanto nas terminaçōes de porfiroclastos rotacionados se formam sombras de pressão assimétricas constituídas por quartzo e feldspatos (Fig. 8b).

As feições indicativas de comportamento frágil e frágil-dúctil são representadas por microfraturas conjugadas que seccionam os cristais, de modo que um porfiroclasto se segmenta em várias lentes menores, as quais foram isoladas por agregados policristalinos (recuperação).

A hornblenda se apresenta na forma de lentes muito deformadas e com significativa transformação para biotita verde e epídoto. Em um estágio avançado dessa transformação, este mineral chega a desaparecer completamente. Além de todas essas feições, observa-se a presença de um bandamento milimétrico representado por alternâncias de faixas ricas em biotita e epídoto com faixas quartzo-feldspáticas.

As rochas deste domínio se caracterizam por uma mudança na coloração, significativa redução do tamanho dos grãos, recristalização dinâmica dos cristais e diminuição do ângulo entre as foliações $\mathbf{S}$ e $\mathbf{C}$, classificando-se como verdadeiros milonitos. As transformaçōes mineralogicas, que acompanham esta progressão da deformação cisalhante, foram também notáveis.

Domínio E As rochas deste domínio também se localizam nas porções centrais das faixas de cisalhamento. Apresentam coloração cinza-escuro a preta, textura afanítica, granulação finíssima a vítrea, constituíndo ultramilonitos e pseudotaquilitos (Fig. 3h, i, j). A foliação milonítica tende a desaparecer devido ao estágio avançado de cominuição em que se encontra a rocha e dá lugar a um aleitamento composicional observado somente nas seções delgadas. Essa microestrutura é definida pela alternância de faixas descontínuas vítreas, escuras, com outras microcristalinas claras. As porções vítreas permeiam irregularmente a rocha, deixando rastros turvos que invadem as partes 


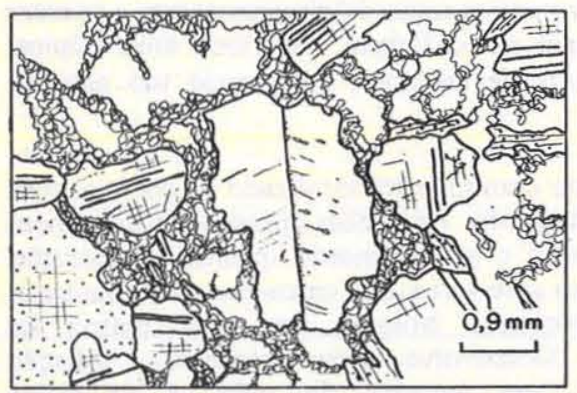

Figura 4 - Aspecto textural mostrando a relação entre os porfiroclastos (microclínio, plagioclásio, anfibólio e algum quartzo) envolvidos por uma matriz granoblástica mais fina recristalizada (domínio B). St́mbolos como na Figura 3

Figura 5 - Porfiroclastos de plagioclásio e microclínio seccionados por microfalhas com recristalizaçāo ao longo delas e formação de kinkband (domínio B). Símbolos como na figura 3

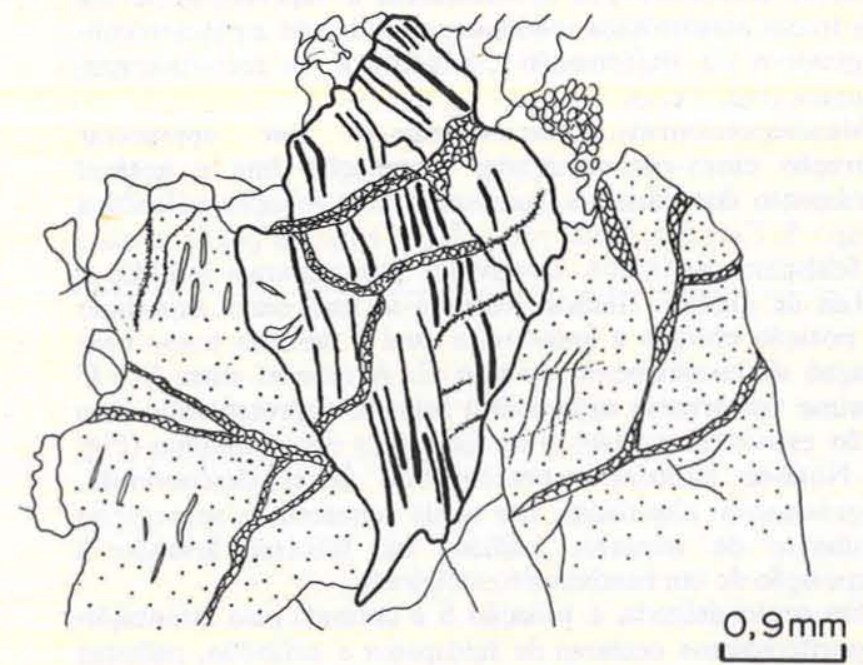

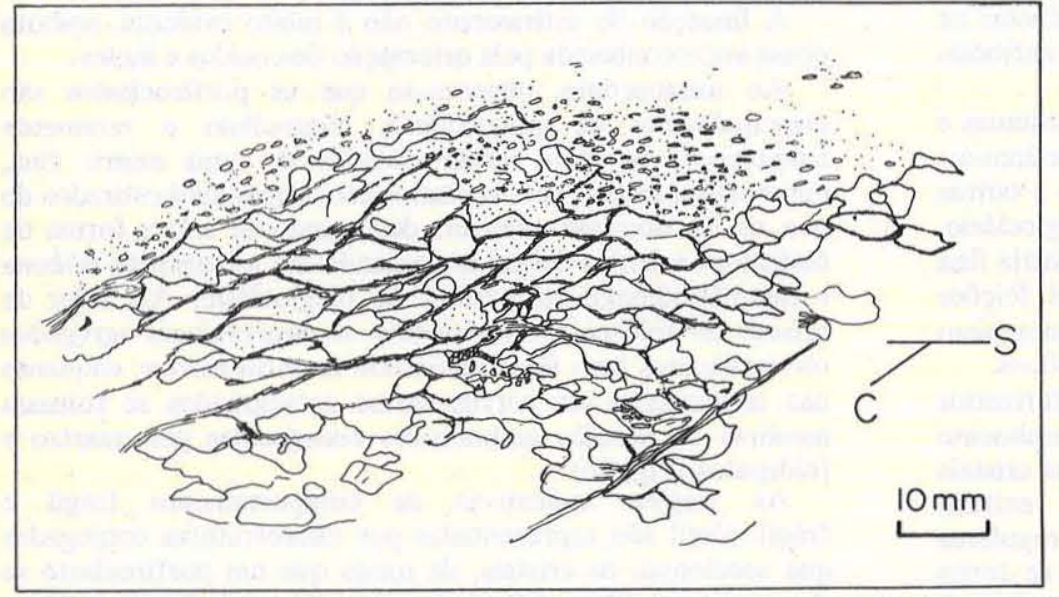

Figura 7 - Cristais de hornblenda recristalizados, nas bordas e nas microfraturas, para pequenas palhetas de biotita verde e epídoto (domínio C). Símbolos como na figura 3

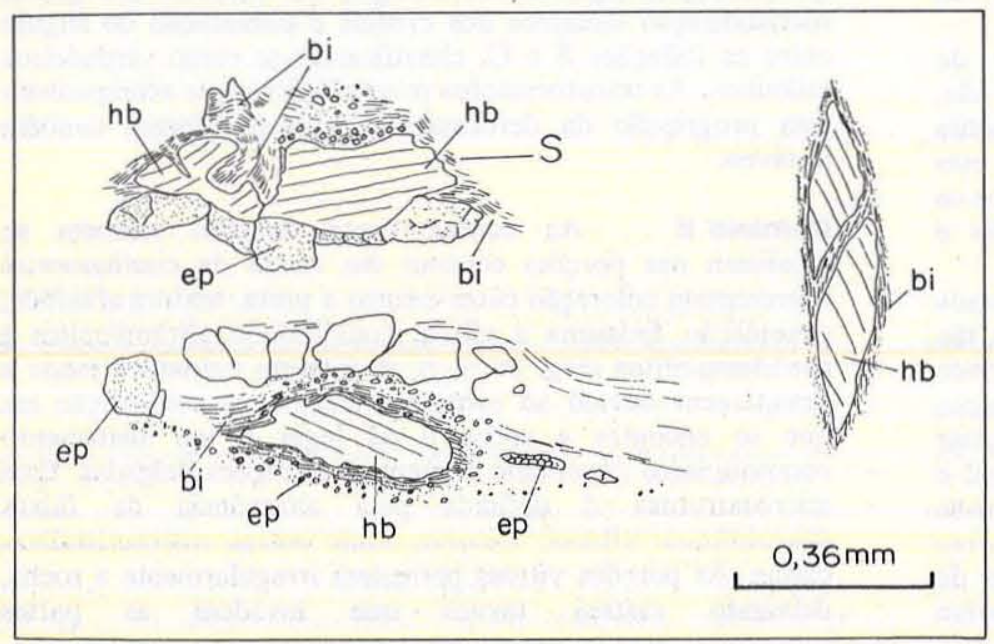

Figura 6 - Aspecto mesoscópico da relação entre as foliações $\mathbf{S} e \mathbf{C}$ em rochas do dominio C. Símbolos como na figura 3

Figura 8 - a. Fatia lentiforme de milonitos com foliação interna $\mathbf{C}$ envolvida pela; $\mathbf{S} ; \mathbf{b}$. sombras de pressão ao redor de porfiroclasto de feldspatos. Símbolos como na figura 3

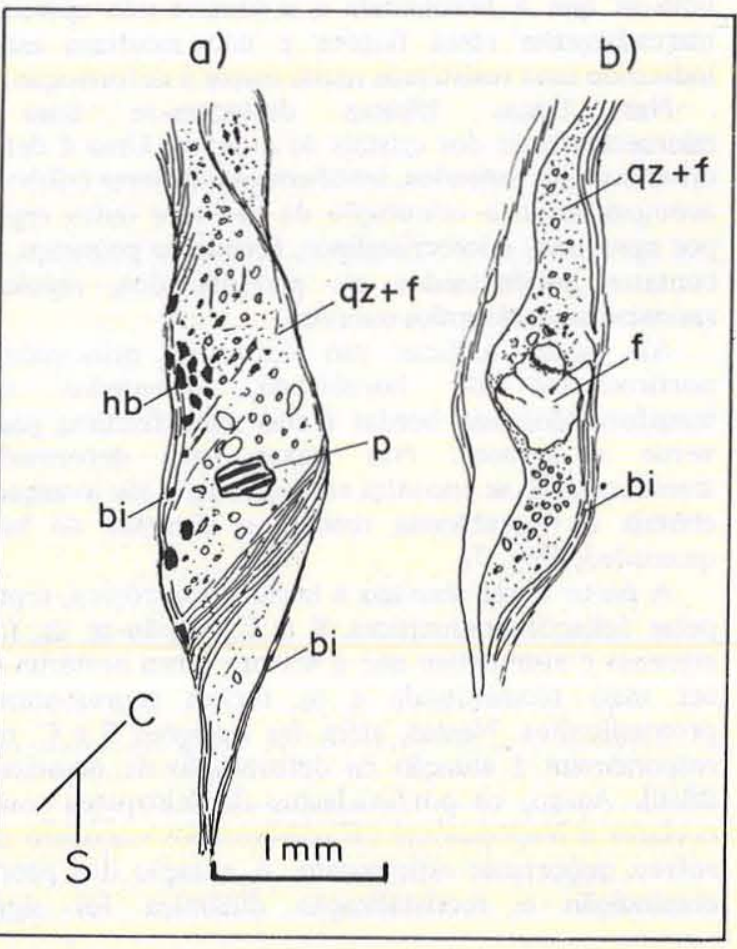


microcristalinas. Nessas porções vítreas são freqüentes microfalhas com aspecto essencialmente frágil. As porçöes claras constituem bandas milimétricas formadas por agregados micro a criptocristalinos, felsíticos. Elas desenham microdobras com padrão geométrico irregular, que provavelmente representam estruturas de fluxo milonítico. Os porfiroclastos sẩo raros, pequenos e principalmente de feldspatos, hornblenda e titanita.

\section{CONCLUSÕES Nos últimos anos têm-se intensificado} os estudos sobre rochas miloníticas face a importância que as mesmas vêm alcançando no entendimento dos processos evolutivos de terrenos metamórficos em diversos cinturões de cisalhamento no mundo, tais como no noroeste da Escócia (Coward \& Park 1987), sudeste da África (Coward 1980, Daly 1986), centro-norte de Goiás (Costa 1985, Gorayeb et al. 1988) e na Amazônia oriental (Araújo et al. 1988).

$\mathrm{O}$ processo de cisalhamento se manifesta pelo aparecimento de faixas e/ou zonas miloníticas cuja penetratividade $e$ função do posicionamento espaço-temporal dos litótipos presentes no cinturâo.

O noroeste do Ceará configura um desse exemplos a nível regional, tendo ali se estabelecido uma entidade geotectônica com movimentação dextral cujos limites, apenas esboçados, se entende desde a região de Sobral (Ceará) até quase São Luís, no Maranhão (Abreu et al. 1988). Neste contexto se posiciona o Granito Pedra do Sal, no qual estão presentes faixas de cisalhamento direcionais estreitas, distribuídas de forma não penetrativa. Essas faixas miloníticas representam os locais de maior concentração de deformação e se pode acompanhar por elas, progressivamente, modificações texturais e mineralógicas importantes, que permitiram a separação de cinco domínios homogêneos, configurando de A a E uma seqüência clássica de deformação progressiva heterogênea, por cisalhamento simples, frágil-dúctil. As modificaçōes da trama original são causadas pela paulatina redução do tamanho dos grãos constituintes, variando a granulometria de grossa a fina, pela segmentação e individualização de novos grãos a partir de cristais maiores, microfraturamento, microboudinage, encurvamento, lenticularização e estiramento de cristais, acompanhados de comimuição e recristalização dinâmica.

A deformação cisalhante gerou toda uma gama de transformaçōes texturais e mineralógicas na rocha original, um monzogranito com seis fases minerais importantes (oligoclásio, microclínio, quartzo, hornblenda, biotita e titanita). Durante a deformação, a maioria dessas fases se reequilibrou aos novos parâmetros de P-T em condiçōes metamórficas na transição da fácies xisto verde alto a anfibolito.

Acompanhando essas feições microtexturais, verifica-se um comportamento diferenciado entre esses minerais em resposta à deformação cisalhante. $\mathrm{O}$ quartzo tem comportamento essencialmente dúctil, apresentando-se a partir do domínio B, com marcante estiramento e significativa recristalização, o que se acentua intensamente nos domínios subseqüentes; os feldspatos, a princípio, são essencialmente frágeis, destacando-se feições em kink e microfraturas, tornando-se frágeis-dúcteis nos estágios mais evoluídos da deformação, mostrando encurvamento e segmentação, acompanhado de lenticularização e recristalização nas bordas (mortar), até se transformarem em lentes e amêndoas. A hornblenda e a titanita, por outro lado, não se deformam ductilmente, tendendo a preservar até o domínio mais evoluído um comportamento frágil. $\mathrm{Na}$ hornblenda, no entanto, a partir do domínio $\mathrm{C}$ ocorre uma transformação em suas bordas e linhas de fraturas para biotita verde e epídoto. Essa recristalização também ocorre na biotita marrom-(primária), a qual tem um comportamento plástico e tende a desaparecer juntamente com a hornblenda com o progresso da deformação cisalhante.

Os pseudotaquilitos ocorrem associados com os ultramilonitos e provavelmente resultam da atuação de processos tardios em condiçöes frágeis.

Devido às poucas informaçôes geologicas acerca do corpo granítico, no que se refere a suas relações com as rochas regionais e a falta de dados petroquímicos, torna-se difícil avançar em consideraçöes petrogenéticas. No entanto, com base nas informaçöes disponíveis sobre outros granitóides regionalmente conhecidos, duas possibilidades podem ser aventadas: a. o corpo corresponderia a uma fácies do Granitóide Chaval, talvez suas porçőes mais externas; ou b. constituir-se-ia um plúton independente semelhante ao Granitóide Ney Peixoto. Considerando-se que a hornblenda fora das zonas de cisalhamento mantém sua feição ígnea inalterada e tendo por base um único resultado de dataçâo de Almeida et al. (1968) sobre esse mineral, de $627 \pm 19 \mathrm{Ma}$, pode-se considerar este dado como representando a idade mínima do corpo. Uma outra alternativa é que esta idade se relacionaria ao processo de cisalhamento presente no corpo, que teria aberto a estrutura cristalina da hornblenda à perda de argônio. Afora as interpretaçōes possíveis sobre o posicionamento do corpo, o fato é que no mesmo se encontra registrado a imposiçâo do Evento Brasiliano, como de resto acontece por tódo o Cinturão de Cisalhamento Noroeste do Ceará.

Agradecimentos Durante os trabalhos de pesquisa que resultaram nessa nota, os autores tiveram o apoio financeiro do Projeto Estudos Geológicos, Geofísicos e Geocronológicos no Cráton São Luís e suas faixas marginais de dobramento (CG-UFPA-Finep) e do Convênio Interuniversidades Subin/UFRN/UFC/UFPA. Na parte logística e operacional, foram de grande importância também os concursos dos departamentos de Geologia e Geoquímica e Petrologia da UFPA, por suas excursőes curriculares. Os autores contaram ainda com a colaboração dos professores-pesquisadores Odete Fátima Machado de Silveira e Ronaldo Lima Lemos, e o apoio técnico dos Srs. Carlos Alberto de Oliveira Lopes e Eduardo Soares.

\section{REFERÊNCIAS BIBLIOGRÁFICAS}

ABREU, F.A.M.; GAMA JÚNIOR, T.; GORAYEB, P.S.S.; HASUI, Y. 1988. O cinturäo de cisalhamento noroeste do Ceará. In: CONGR.LAT.AM.GEOL., 7, Belém. 1988. (no prelo)

ALMEIDA, F.F.M.; MELCHER, G.C.; CORDANI. U.G.: KAWASHITA, K.; VANDOROS, P. 1968. Radiometric age determinations from northern Brazil. Bol.Soc.Bras.Geol. 17(1):3-14.

ARAÚJO, O.J.B.; MAIA, R.G.N.; JOÃO, X.S.J.; COSTA, J.B.S. 1988. A megaestruturação da Folha Serra dos Carajás. In: CONGR.LAT.AM.GEOL., 7, Belém. 1988. (no prelo)

BELL,T.H. \& ETHERIDGE, M.A. 1973. Microstructure of mylonites and their descriptive terminology. Lithos, 6:337-348.

BELL, T.H. \& ETHERIDGE, M.A. 1976. The deformation and recrystallization of quartz in a mylonite zone, central Australia. Tectonophysics, 32:235-267.
CORDANI, U.G.; BRITO NEVES, B.B.de; FUCK, R.A.; PORTO, R.; FILHO, A.T.; CUNHA, F.M.B. 1984. Estudo preliminar de integraçâo do pré-cambriano com os eventos tectônicos das bacias sedimentares brasileiras. Rio de Janeiro. Cenpes/Sintep, 15:11-70.

COSTA, J.B.S. 1985. Aspectos lito-estruturais e evoluçâo crustal da regiäo centro-norte de Goiás. Belém, 210p. (Tese de Doutoramento, CG-UFPA)

COSTA, M.J.; FRANÇA, J.B.; LINS, C.A.C.; BACCIEGGA, I.F.; HABEKOST, C.R.; CRUZ, W.B. 1979. Geologia da Bacia Jaibaras Ceara, Piaut e Maranhäo. Projeto Jaibaras. Brasília, MME/DNPM. 106p.

COWARD, M.P. 1980. Shear zones in the precambrian crust of southern Africa. J. Struct. Geol., 2:19-27.

COWARD, M.P. \& PARK, R.G. 1987. The role of mid-crustal shear zones in the early proterozoic evolution of the Lewisian. In: 
PARK, R.G. \& TARNEY, J. Evolution of the Lewisian and comparable precambrian high grade terrains. Spec.Publ.Geol.Soc. London, 27:127-138.

DALY, M.C. 1986. The intracratonic Irumide Belt of Zambia and its bearing on collision orogeny during the proterozoic of Africa. In: COWARD, M.P. \& RIES, A.C. Collision tectonics. Spec.Publ.Geol.Soc. London, 19:321-328.

GORAYEB, P.S.S.; COSTA, J.B.S.; LEMOS, R.L.; GAMA JÚNIOR, T.; BEMERGUY, R.L.; HASUI, Y. 1988. O pré-cambriano da regiâo de Natividade, GO.Rev.Bras.Geoc. 18(4):391-397

HASUI, Y.; ABREU, F.A.M.; VILLAS, R.N.N. 1984. Província Parnafba. In: ALMEIDA, F.F.M. de \& HASUI, Y. $O$ Pré-Cambriano do Brasil. São Paulo, Blücher. p.36-45.

HIGGINS, M.W. 1971. Cataclastic rocks. U.S. Geol. Surv. Prof. Pap., 687:1-97.

LESOUER, A.; BELTRĀO, J.F.; ABREU, F.A.M, 1984. Proterozoic links between northeastern Brazil and west Africa: a plate tectonic model based on gravity data. Tectonophysics, 110:9-26.

MITRA, G, 1978. Ductile deformation zones and mylonites, the mechanical processes involved in the deformation of crystalline basement rocks. Am. J. Sci.. 278(8): 1057-1084.

MITRA, G. 1979. Ductile deformation zones in Blue Ridge basement rocks and estimation of finite strains. Bull. Geol. Soc. Am., 90:935-951.
SIBSON, R.H. 1977. Fault rocks and fault mechanisms. J.Geol.Soc. London, 133:191-213.

SPRY, A. 1969. Metamorphic textures. London, Pergamon Press. 350p. STRECKEISEN, A.L. 1976. To each plutonic rock its proper name. Earth Sci.Rev., 12:1-33.

VILLAS, R.N.N. 1982. Geocronologia de intrusōes f́gneas na bacia do rio Guamá, nordeste do Estado do Pará. In: SIMP.GEOL.AMAZ., 1, Belém, 1982. Atas... Belém, SBG. v. 1, p.233-247.

WHITE, S. 1976. The effect of strain on the microstructures, fabrics and deformation mechanisms in quartzites. Phil. Trans. R. Soc. London, 283:69-86.

WHITE, S. 1977. Geological significance of recovery and recrystallization processes in quartz. Tectonophysics, 39:143-170.

WHITE, S.H.; BURROWS, S.E.; CARRERAS, J.; SHAW, N.D.; HUMPHREYS, F.J. 1980. On mylonites in ductile shear zones. $\vec{J}$. Struct. Geol., 2:175-187.

\section{ERRATA \\ PARTICIPANTES INSCRITOS NO ISGAM}

ONDE SE LÊ

1. VASCONCELOS, ANA OSMIRO

2. SINDING-LARSON, R.

3. WEINBERG, ROBERTO FERREZ

4. SCHLAG, CHISTIAN F.O.

5. SCISLEWKI, GILBERTO

6. REGO, BEATRIZ MARIA S.

7. PARADA, MICHEL ANGEL

8. PRATES, SÔNIA

9. COUTO, PEDRO ALMEIDA

10. KLEMD, CHAMBER

11. PEREIRA, HILTON

12. NARDI, LAURO VALENTIM STOLL Rua Amélia Teles, 367/402

13. CAMPELO, ROBERTO

Rua Visconde de Itaporai - Amaralina

1. WADJINNY, AHMED

Compagnie Minière de Touissit

5, Rue IBN Tofail

Casablanca - Morocco

2. SOARES FILHO, CLAUDEMIRO PIRES Rua Lauro de Freitas, 127 - São Cristóvão 41500 - Salvador - Bahia - Brazil

\author{
LEIA-SE \\ VASCONCELOS, ANA OSMIRA \\ SINDING-LARSEN, R. \\ WEINBERGER, ROBERTO FERREZ \\ SCHLAG, CHRISTIAN F.O. \\ SCISLEWSKI, GILBERTO \\ REGO, BEATRIZ MARTINS S. \\ PARADA, MIGUEL ANGEL \\ PRATES, SÔNIA \\ NUCLEBRÁS \\ COUTO, PEDRO ALMEIDA \\ KLEMD, REINER \\ PEREIRA, HELTON \\ NARDI, LAURO VALENTIM STOLL \\ Rua Amélia Teles, 367 - Apt ${ }^{\circ} 403$ \\ CAMPELO, ROBERTO \\ Rua Visconde de Itaboraí - Amaralina
}

\section{INCLUSŌES}

3. RUHLMANN, FRANÇOIS COGEMA

2, rue Paul Dautier, BP no 4

79141 Velizy - Villa Coublay - France

4. ALONSO, JOSÉ MANUEL DOMINGUEZ Av. 7 de Setembro, 1894/901 - Vitória 40120 - Salvador - Bahia - Brazil

... a principal contribuição da Geoquímica para a indústria mineral não está nos modelos em si mesmos, mas em enfatizar as perturbaçōes geoquímicas dos sistemas rochosos associados aos depósitos. 